\title{
Mobile phones in Africa: how much do we really know?
}

\author{
Jeffrey James $\cdot$ Mila Versteeg
}

Received: 23 September 2006/ Accepted: 21 November 2006/Published online: 4 January 2007

(C) Springer Science+Business Media B.V. 2007

\begin{abstract}
Mobile phones are a crucial mode of communication and welfare enhancement in poor countries, especially those lacking an infrastructure of fixed lines. In recent years much has been written about how mobile telephony in Africa is rapidly reducing the digital divide with developed countries. Yet, when one examines the evidence it is not at all clear what is really happening. In one country, Tanzania, for example, some observers point to the fact that $97 \%$ of the population lives under the mobile footprint, while others show that ownership is very limited. These extreme values prompted us to review the situation in Africa as a whole, in an effort to discover what is really going on.
\end{abstract}

Keywords Concepts of mobile reach in developing countries - Mobile footprint · Africa as a special case $\cdot$ Implications for digital divide

\section{Introduction}

Mobile telephony is considered to be particularly important for development, especially in countries lacking a fixed-line infrastructure. There is some evidence that mobile phones raise long-term growth rates, that their impact is twice as big in developing nations as in developed ones, and that an extra ten phones per 100 people in a typical developing country increases GDP growth by $0.6 \%$ points (Waverman, Meschi, \& Fuss, 2005). Many see mobiles as an opportunity for developing countries to close the digital divide, especially in Africa. Yet, we do not seem to possess consistent data on mobile phones in Africa. Different organizations and authors use different definitions. Examination of the available data reveals that it is often still unclear what is meant by it-and what not. Moreover, as a result of different definitions and concepts there are many different figures on the presence of 
mobile phones, ranging from almost 0 in the narrowest definition (ownership) to almost $100 \%$ in the broadest definition (access).

These differences matter, among other reasons, because they inform national policy making towards the sector and international efforts to bridge the digital divide between Africa and other parts of the world. This paper accordingly seeks to clarify the conceptual confusion that underlies the grossly different estimates of the extent to which mobile telephony exists on the continent. To this end we employ a framework that distinguishes between mobile phone subscribers, mobile phone owners, mobile phone users, those who benefit from usage and those who have access to this technology. This classification, we feel, will provide the reader with a better understanding of the state of mobile telephony in Africa and will have important implications for the type of data that are needed, but at present are unavailable. The categories that are identified, moreover, help us better to understand different views as to the extent of the digital divide in mobile phones between Africa and the rest of the world.

\section{A classification of the ways in which individuals relate to mobile phones}

\subsection{Mobile phone subscribers}

The only data that are readily available on mobile telephony in Africa are data on the number of subscribers, provided by mobile phone companies. The number of subscriptions per 100 inhabitants comprises the penetration rate. The average penetration rate in Africa is $6.2 \%$. The highest penetration rates can be found in Reunion (74.7\%), Seychelles (68.4\%), Mauritius (37.9\%) and South Africa (36.4\%). The lowest penetration rates can be found in Ethiopia, Guinea Bissau (both $0.1 \%$ ), the Central African Republic, Comoros (both 0.3\%), Chad (0.8\%) and Burundi $(0.9 \%)$ (Vodafone, 2005). However, these figures do not necessarily tell us anything about the importance of mobile phones in Africa. Most notably, and especially in Africa, they do not capture mobile phone usage, as there will almost certainly be considerably more users than mobile subscribers.

But since the $6.2 \%$ average penetration rate is the most reliable figure, it is often used to represent the African situation. This is unwarranted, however, because it is based on Western logic which equates subscribers with users. For instance, a recent article by the $\mathrm{BBC}$ notes that the proportion of people in Africa using mobile phones is low in international terms, averaging about 6\% in 2004 (BBC News, 2005a, b). Or, again, a recent UNCTAD report (2005) illegitimately employs the number of mobile subscriptions to draw conclusions on mobile phone usage (UNCTAD, 2005, p. 12). Interestingly however, the same UNCTAD report does distinguish between subscriptions to and usage of the Internet. It uses an estimate of number of users per subscriber to calculate the number of Internet users. In our opinion, such a distinction between subscriptions and usage should also be made for mobile phones, where the differential could actually be much higher (see below under: implications for data collection). Especially in Africa, with its culture of sharing, mobile phones are often divided among people. So the actual number of users is likely to be much higher than $6 \%$. At the same time it is possible to subscribe to mobile phone services without actually buying a phone. It is possible, in particular, just to buy a pre-paid 
SIM card, which can be used in other people's telephones. Hence, subscribers also have to be distinguished from owners.

\subsection{Mobile phone owners}

As a general rule, it can be assumed that those who have a mobile phone subscription generally also own a mobile telephone. But, as noted in the previous section, this is not necessarily the case. In sub-Saharan Africa, more than $90 \%$ of the mobile subscribers have a pre-paid subscription. In fact, it has been argued that the real break-through of mobile telephony in Africa has been the introduction of prepaid services that do not require monthly payment, but make payment dependent on usage. Pre-paid subscriptions are appealing to people with lower or irregular incomes, since their use does not require a bank account, a physical address, a postal address or a minimum fixed monthly subscription fee (Gillwald, 2005, p. 23). At the same time, it is important to note that pre-paid SIM cards are also being sold without ownership of a telephone. In this respect, a study on telecommunications in Ethiopia notes that there is an innovative market for selling SIM card rights and renting SIM cards in Dire Dawa and Addis Ababa (Adam, 2005). For instance, there is a practice of owning more than one SIM card as a means of generating income. The study describes an example of someone who owns three SIM cards, rents out two of them and uses the income to cover the costs of the third. In addition, the study describes that individuals who have just acquired their SIM card often keep the card for a while instead of using it, as they are still unable to buy a mobile phone or because they want to make optimum use of the air time that is included in the pre-paid subscription (Adam, 2005, p. 88).

As a result of these practices, it is quite likely that some of the mobile phone subscribers do not own a phone. Or put differently, the mobile phone penetration rates might be an overstatement of the actual number of phone owners, just as they are an understatement of the number of users. Unfortunately however, there is no evidence which can tell us the percentage of pre-paid subscribers that also owns mobile phones. A Celtel spokesman we talked to in the Netherlands, argued that the people that currently have subscriptions are the first movers who have the money not only to buy a SIM card, but also a mobile phone. In his opinion the number of subscribers is very close to the number of owners. However, there are no data available that confirm his argument. In addition, even if this is the case, it is not unlikely that as mobile telephony becomes increasingly common in Africa, there will be more people with relatively low incomes who will buy SIM cards without a mobile phone and will borrow someone else's phone to use the card.

However, as with subscription figures, figures on mobile phone ownership provide little information on the importance of mobile telephony in Africa. Due to the sharing (of either the phone or the SIM card and the phone) ownership figures are likely to be a severe understatement of the number of users.

\subsection{Access to mobile phones}

If data on mobile phone ownership are thus difficult to obtain, this is less true of data on access. "Access" refers to the percentage of people that potentially could use a mobile phone as they are within the range of a mobile network. The concept of access has recently gained importance within the framework of the UN and the 
World Bank. The UN has set a goal of $50 \%$ access by 2015 . Some commentators have gone so far as to suggest that "the digital divide that really matters then, is between those with access to a mobile network and those without" (Economist, 2005). With respect to this concept, moreover, some quite optimistic figures have been presented. A recent World Bank report for example notes that $77 \%$ of the worlds' population already lives "under the footprint of a mobile network" (World Bank, 2005). In the African context there are some even more optimistic figures. In several documents it has been estimated that $97 \%$ of the people in Tanzania have access to a mobile phone. In our opinion however such data provide little information on the importance of mobile phones in a country. Potential access to a network for poor people that might not even have family or friends whose mobile phone they can share, does not seem a very meaningful concept. Being under the footprint of a mobile network of course might have important advantages for doing business in such a country. But it is not directly beneficial for the large majority of the African people. Or, put differently, it is a necessary condition for using mobile phones, but not sufficient for actual usage.

Let's return to the example of Tanzania. Apparently 97\% of that country is under the footprint of a mobile network (Vodafone, 2005). But at the same time, Tanzania's penetration rate is only $2.5 \%$. This implies that probably less than $2.5 \%$ of the population owns a phone. There is not much reliable data on the extent of mobile phone sharing, though a household survey in Tanzania, sponsored by Vodafone, suggests that there are as many users as there are owners. If correct-in fact the Vodafone methodology does not seem entirely sound-this would imply that $5 \%$ of the population actually uses a mobile phone. Needless to say, the differences between $2.5 \%$ owners, $5 \%$ users and $97 \%$ access are rather substantial and, depending on whether the goal of policy is to increase usage or access, would have vastly different implications.

\subsection{Mobile phone users}

If one is interested in the effects of mobile telephony on development, one is probably most interested in the number of mobile phone users and the benefits they derive. How many people do actually use mobile phones? How many people benefit from the advantages of mobile phone usage, for instance in doing business? Of course, phone owners use their phones, but usage is not limited to owners. We define users as those who use mobile phones at least once every 3 months, either through ownership or through sharing.

It is paradoxical that although usage data are the most important in our view, they are also the most difficult to obtain. As noted before, penetration rate data are often presented as data on mobile phone usage. But in the African context, the Western idea that only those who own a phone can use one is not at all accurate, since the phenomenon of "sharing" is of particular importance. Many phone owners in poor communities share their mobile phones. In Botswana for instance, household surveys reveal that $62.1 \%$ of the phone owners share their phones with their family, $43.8 \%$ with their friends and $20 \%$ share their phone also with their neighbours. Moreover, only $2.2 \%$ of the phone owners actually charge for the use of their mobile phones (Sebusang et al., 2005). Similar figures on sharing and charges for the sharing are available for Namibia (Stork, 2005, p. 112). The Vodafone study also stresses the importance of sharing in Africa "We have learned that people in Africa use mobile 
phones very differently. Most striking is the accessibility of mobile phones. While penetration rates are by the standards of developed world countries very low, the way in which mobiles are informally shared between people, the formation of private resellers of mobile services and the provision of mobile phones for public use, all increase accessibility, even in rural communities. The impact of mobiles extends well beyond what might be suggested by the numbers of subscribers alone" (Vodafone, 2005, p. 2).

At present, however, we are severely lacking in data that reflect usage at the country level. And even if we had such data for a few countries, it could not be extrapolated to the continent as a whole. For instance, there is the household survey in Tanzania that indicates that there for every owner there is one additional user (Vodafone, 2005). If we knew exactly how many owners there are, which should be somewhere between 0 and $6 \%$ on average in Africa, we could multiply this number by 2 in order to get the number of users. A study by Gillwald however, based on household surveys in ten different African countries indicates that the extent of sharing might significantly differ per country. For instance, in South Africa there is much less sharing than in Namibia. This could probably be explained by the fact that South Africa has got a significantly higher penetration rate. But it shows that a simple thumb rule for estimating the number of users in relation to the number of owners might not be applicable to the entire continent. It must be noted also that there is more sharing in the rural than in the urban areas. According to Gillwald, in all ten countries surveyed, "the drop-off between urban and rural areas is dramatic."

Unfortunately the Gillwald study fails to provide consistent data on the different countries-there is information on sharing only for some countries-and does not indicate how often phones are shared and with how many people. It does reveal for instance that phones are mainly shared with family, friends and neighbours, but it does not mention how often they are shared and does not provide information on the number of family, friends and neighbours that are allowed to share the phone (Gillwald, 2005).

If one wants an impression of the extent of mobile phone sharing in Africa, it is probably most useful to distinguish between commercial and non-commercial use. Non-commercial sharing of mobile phones consists of the sharing of privately owned mobile phones with family, friends and neighbours, as described above. The vast majority of phone owners that share their phones do not charge these users anything. But, as also noted before, there is no universal metric that translates the number of owners into the number of users.

Commercial sharing consists of mobile phone services that are available to people after payment. Important examples of commercial sharing are the Grameen village phone project and mobile phone kiosks. The village phone project was initiated by the Grameen Bank in Bangladesh. It offers women low-cost loans to set up a mobile phone exchange in villages where there are few, if any, landlines. The project is widely considered as a great success. For the phone ladies it offers a higher income, while the villagers are provided with the possibility to use a mobile phone and to pay per minute. The project started in Bangladesh, but the Grameen Bank has set up a similar project in Uganda. According to the Grameen Bank, the village phones are on average shared among approximately 70 people. Or, put differently, one phone owner/subscriber comprises 71 users. Mobile phone kiosks work in a more or less similar fashion. In most African countries, there are privately owned kiosks that sell mobile phone air time vouchers. It is a lucrative business and a large market has 
been formed. In Botswana for instance, these private mobile phone kiosks are by far the most used public phones $(84.8 \%$ of public phone calls are being made in these kiosks). Also, $51.8 \%$ of the people in Botswana have phone kiosks within 5 minutes of their houses (Sebusang et al., 2005, p. 41).

So far, it has been suggested that if one is interested in the impact of mobile telephony on development, one should collect data on how many people actually use mobile phones. Counting the number of those who actually benefit from mobile telephony (the users) seems far more sensible than counting the number of owners. Even then however, such an approach does not capture differences in usage in terms of both quantity and quality between the developed and the developing world.

In general it might be argued that both the quality and quantity of mobile phone usage is lower in the developing world than in developed countries. First, as far as quantity is concerned, it is likely that users in developing countries, especially nonowning users, use a mobile phone less frequently than users in developed countries. Indeed, the influence of income on the extent of usage is apparent even from the comparison within developing countries. Household surveys conducted by Vodafone in Tanzania and South Africa show for instance that $76 \%$ of the mobile owners in these respective countries use their mobiles four times a week or more. But in contrast, of the non-owning users (with generally lower income), only $24 \%$ in South Africa and $16 \%$ in Tanzania use a mobile four times a week or more. Similarly, in developing countries it might be expected that the average time spent on a conversation is shorter. This is suggested also by all the "beeping signals" that have been developed to save use time. And in turn, within the developing countries, it might be expected that owning-users have a higher average calling time than nonowning users.

Second, with regard to quality, it might be expected that the quality of mobile phone usage in developing countries is lower than in developed countries. An UNCTAD report rightly notes that, "In developed countries, mobile handsets are developing into multi-media devices capable of delivering email, photographs and the real-time exchange of information. In developing countries, the reality might be very different, with shared or collective access and widespread use of 'beeping' (to notify recipients of a missed call, so they can call back). Users in different countries and cultures are finding their own way to use new technologies" (UNCTAD, 2005, p. 12). In this respect, Gillwald concludes that African users pursue a "multiple communications strategy." They utilize whatever medium of communication is available, and they use them in different ways depending on two key factors: convenience (or accessibility) and disposable income at that particular period. As a result, African users might use public access phones, mobile phones, mobile phone kiosks and traditional landlines alike. For instance, a communication expenditure of around US $30 \mathrm{c}$ in the middle of the month means that a personal mobile phone is unlikely to be used but that some airtime will be bought from a mobile phone kiosk (Gillwald, 2005, p. 18).

However, different types of usage are characterized by different levels of quality. For instance, if someone makes phone calls by means of borrowing someone else's phone, this implies that he or she only can make an outgoing phone call but cannot receive an incoming call. Being able to receive incoming calls too however, would certainly add extra value, which the non-owning users of the developing world fail to capture. 
Furthermore, mobile phones are often used in creative ways so as to avoid costs. In this respect the phenomenon of beeping deserves mentioning. For instance, beeping once might mean that the person is at a certain meeting point, whereas beeping twice might mean that there is a half-an-hour delay. But one beep might also be a signal for saying "hello." In this fashion, using a mobile phone becomes costless.

\section{Implications}

\subsection{Implications for data collection}

As emphasized in the previous section, it is on usage (rather than ownership) that data collection needs to focus, because this concept comes closest to capturing the benefits that are actually derived from mobile phones. As was also apparent in that section, however, such a task would be a formidable one, involving as it must, the subtle ways in which mobiles are shared in the region. At the country level, there are scattered data that throw some light on the issue, but these are derived from research on other related topics rather than from studies that are dedicated specifically to estimating the number of users at this level. Cross-country data typically skirt the issue entirely by focusing exclusively on ownership or access. There is thus very little basis on which to estimate whether the extent of usage will lie closer to ownership (at the one extreme) or access (at the other). Such evidence as there is, moreover, indicates that there might well be important differences between African countries in this regard, thus making it unhelpful to simply multiply the number of owners in each country by a given number (as is now the case with measures of Internet use across countries). For the future, however, there is some reason to be hopeful about getting an indicator of usage that differentiates between African (and other) countries. Our optimism resides in an initiative that emerged from the World Summit on The Information Society in 2003. In particular, a number of international institutions formed a Partnership on Measuring ICT for Development, one of whose tasks was to develop a core list of ICT indicators, which "could be collected by all countries and serve as a basis for internationally comparable statistics on the information society" (United Nations, 2005). The list that emerged in 2005 contained a "basic core" and an "extended core." In the former one finds the traditional measures of mobile phone ownership and access, but in the latter there is a category entitled "proportion of individuals with use of a mobile telephone." The Partnership suggests that this indicator be measured in relation to answers obtained in response to the question "Did you have personal use of a mobile phone during some or all of the last 12 months?" It is true that this indicator is as yet only a proposal, but it does indicate a recognition on the part of major international institutions that mobile use should appear in cross-country data.

\subsection{Implications for the digital divide}

In this section, we will examine the implications of our classification scheme for the digital divide. Traditionally, in measuring the digital divide it is assumed that only those who actually own a certain ICT device use it. For instance, the number of Internet connections in the developing world is compared with the number of 
Internet connections in the developed world. And as far as mobile phones are concerned, the number of subscriptions in the developing world is compared to the number of subscriptions in the developed world. However, as a result of the different types of mobile phone usage in the developing world, most notably the informal sharing among friends and families and the commercial sharing through kiosks, such an analysis might result in a severe overstatement of the digital divide. As noted above, it is not just $6 \%$ of Africans that use a mobile phone. As a result of sharing, the true number of users is likely to be substantially higher than $6 \%$. The same reasoning applies if the number of mobile phone owners in the developing world are compared to the number of owners in the developed world. This comparison too will result in an overstatement of the digital divide.

In contrast, if access data are used, they will show that the digital divide is substantially smaller. If $77 \%$ of the global population already lives under the footprint of a mobile network, the differences between the developing and the developed world are relatively small. In fact, the comparison of access data is likely to result in an understatement of the digital divide since many people that have access to mobile phones do not use them.

This paper builds on the belief that usage data gives the most accurate picture of the digital divide. However, since these data are generally unavailable, we do not have a clear idea of the actual size of the digital divide. Moreover, it should be emphasized that usage data give an idea of how many people actually benefit from ICT, they do not reveal how and how much they benefit. In this respect, because of the influence of income, both the quantity and quality of usage are expected to be lower in developing countries. Therefore if these issues are taken into account, the size of the digital divide increases once again. For instance, usage data could show that $30 \%$ of the population in Africa as compared to $90 \%$ in Europe use a mobile phone. However, whereas the average European might make a call three times a day, the average African might make a call once a week. Similarly, the quality of the calls will generally be lower. Often, only a few words are exchanged in a brief conversation. Moreover, the phone connection might be poor and the quality of the phone itself might be lower. Nevertheless, despite these differences, usage data currently seem to give the most accurate picture of the importance of mobile phones in Africa. As noted above, however, it is exactly these data that are most scarce. And there are few efforts underway to collect these data, despite a growing global awareness of the importance of ICT indicators for Africa. (One partial exception being the proposal to gather a consistent set of mobile use statistics by the Partnership on Measuring ICT for development noted above.) What can be done, however, is to show the direction of influence exerted by each of the categories we have defined on the digital divide (note too that the poor comprise different occupational and locational groups, which, as noted by Stavrou and Mkhize (1998), tend thus to relate in different ways to alternative policies designed for their benefit) (Table 1).

\section{Conclusions}

What we most urgently need to know about mobile phones in Africa is neither the number of owners nor the number of those with access to this technology. It is rather the number of users, a figure which will lie somewhere between the two. At present, however, we have no reliable basis on which to assess whether the extent of usage 
Table 1 How we measure mobile phone influences the digital divide

\begin{tabular}{ll}
\hline $\begin{array}{l}\text { Categories of mobile } \\
\text { phone beneficiaries }\end{array}$ & $\begin{array}{l}\text { Digital divide in } \\
\text { mobile phones }\end{array}$ \\
\hline Ownership & Overstatement \\
Subscribers & $\begin{array}{l}\text { Overstatement } \\
\text { Access }\end{array}$ \\
Usage & Best estimate \\
Quantity: calling time & Digital divide increases \\
Quality & Digital divide increases
\end{tabular}

will lie closer to the one extreme category or the other. In particular, the required data are unavailable at both the country and cross-country levels. The problem is partly that country level research has not addressed itself to this specific question and partly that such fragments of evidence as do exist, indicate that there might well be quite important differences between African countries from this point of view (thus making it unhelpful to simply multiply the number of owners in each country by a given multiple). Existing measures of Internet use across countries suffers from this methodological weakness, which would be even more problematic in the case of mobile phones. In sum then, what we know about mobile phones in Africa falls far short of what we need to know, and this difference presents a large research gap that needs to be filled (one that would include finding a more realistic estimate of the global digital divide in mobile phones, with particular reference to countries in sub-Saharan Africa).

\section{References}

Adam, L. (2005). Ethiopia. In A. Gillwald (Ed.), Towards an African e-index; household and individual ICT access and usage across 10 countries in Africa. Johannesburg, South Africa: The Link Centre, Witwatersrand University.

BBC News. (2005a). Mobile growth fastest in Africa. Retrieved from http://news.bbc.co.uk/1/hi/ business/4331863.stm.

BBC News. (2005b). Africa's mobile entrepreneurs. Retrieved from http://news.bbc.co.uk/1/hi/ business/4145435.stm.

Economist. (2005). The real digital divide, March 10th.

Gillwald A. (Ed.). (2005). Towards an African e-index; household and individual ICT access and usage across 10 countries in Africa. Johannesburg, South Africa: The Link Centre, Witwatersrand University.

Sebusang, S., Masupe, S., \& Chumai, J. (2005). Botswana. In A. Gillwald (Ed.), Towards an African e-index; household and individual ICT access and usage across 10 countries in Africa. Johannesburg, South Africa: The Link Centre, Witwatersrand University.

Stavrou, A., \& Mkhize, K. (1998). A telecommunications universal service policy framework for defining categories of needy people in South Africa. Johannesburg: South African Telecommunications Regulatory Authority.

Stork, C. (2005). Namibia. In A. Gillwald (Ed.), Inwards on Africa e-index, household and individual ICT access and usage across 10 countries in Africa. Johannesburg, South Africa: The Link Centre, Witwaterstand University.

UNCTAD. (2005). The digital divide: ICT development indices 2004. New York and Geneva: United Nations.

United Nations. (2005). Core ICT indicators. Partnership on Measuring ICT for Development. Geneva:WSIS.

Vodafone. (2005). Africa; the impact of mobile phones. Moving the debate forward (Vodafone Policy Papers Series No. 2). Vodafone Group. 
Waverman, L. Meschi, M., \& Fuss, M. (2005). The impact of telecoms on economic growth in developing countries. In Vodafone, Africa; the impact of mobile phones. Moving the debare forward (Vodafone Policy Papers Series No. 2).

World Bank. (2005). Financing information and communication infrastructure needs in the developing world; public and private roles. Washington, DC: Global Information and Communications Technologies Department. 